\title{
NUEVOS REGISTROS CON NOTAS ECOLÓGICAS Y TAXONÓMICAS DE ESPONJAS DULCEACUÍCOLAS (PORIFERA, SPONGILLIDAE) EN LA CUENCA DEL DUERO
}

\author{
Javier Morales $^{*} \&$ Ana Isabel Negro** \\ * Área de Biología Animal. Universidad de Salamanca, Campus Miguel de Unamuno. \\ 37007 Salamanca, España. E-mail: mormarja@usal.es \\ ** Área de Ecología. Universidad de Salamanca, Campus Viriato. 49022 Zamora, España
}

\section{RESUMEN}

El trabajo supone la primera contribución al conocimiento ibérico de las esponjas de agua dulce (Porifera, Demospongiae, Spongillidae) en la cuenca del Duero. Se encontraron ejemplares en $24(+)$ de 32 transectos, repartidos en 16 estaciones de muestreo. El estudio se desarrolló en 6 subcuencas fluviales de la meseta norte y fueron obtenidos datos sobre su ecología y distribución en 25 tramos fluviales vadeables $(20+/ 5-)$ y en 7 humedales profundos (4+/3-). Se localizaron ejemplares vivos durante las épocas de estiaje y se identificaron mediante la observación al microscopio de las espículas silíceas cuatro especies: Ephydatia fluviatilis, $E$. muelleri, Heteromeyenia baileyi y Spongilla lacustris. La máxima riqueza de especies se presentó en el curso medio del río Negro, donde se hallaron tres especies en simpatría. E. muelleri fue localizada por primera vez en la cuenca del Duero en un tramo del río Aliste. H. baileyi mostró preferencia por aguas someras y corrientes, y únicamente se localizó sobre rocas duras (cuarzitas). S. lacustris y E. fluviatilis fueron localizadas tanto sobre sedimentos compactados, rocas o maderas sumergidas y en un amplio rango de profundidades. E. fluviatilis no se localizó en lagunas de alta montaña, siendo una especie habitual en ríos. $H$. baileyi y $S$. lacustris mostraron preferencia por ríos de aguas ácidas y baja mineralización; mientras que ambas especies de Ephydatia se hallaron en aguas algo mineralizadas. Se discute la influencia de estos parámetros ambientales en la distribución encontrada y su presencia en sintopía con otros invertebrados indicadores de condiciones de oligotrofia, acidez y elevada oxigenación.

Palabras clave: ecología; distribución; ríos y lagunas; esponjas; cuenca Duero.

\section{ABSTRACT}

New records of freshwater sponges (Porifera, Spongillidae) from Douro River basin, with ecological and taxonomic notes

This work is a contribution to the knowledge of freshwater sponges (Porifera, Demospongiae, Spongillidae) of the Douro River watershed. Specimens were found in 24 of 32 transects in 16 sampling stations. Distribution and several ecological data were obtained in 25 wadeable river transects $(20+/ 5-)$ and 7 deep lakes $(4+/ 3-)$ of six sub-basins of the northern Iberian plateau. Four species (Ephydatia fluviatilis, E. muelleri, Heteromeyenia baileyi and Spongilla lacustris) were recorded throughout the survey during successive dry sessions and classified by microscopic observation of siliceous sclera. The maximum species richness was found in the Negro River, where sympatric coexistence was detected in three species. E. muelleri was only found in the Aliste River, and it is the first record of this species in the Douro basin. H. baileyi showed a preference for shallow areas in flowing waters, and was only present on hard stony substrates (quartzites). S. lacustris and E. fluviatilis were found on compacted sediments, rocks and submerged wood substrates, and in a wide interval of depths. E. fluviatilis was absent in mountain lakes, whereas it was the most frequent species in rivers. H. baileyi and S. lacustris showed preference for acidic and low mineralization rivers, while both species of Ephydatia for more mineralized waters. The influence of chemical water and other environmental parameters on the distribution range of each species and its presence in syntopy with other invertebrate indicators of oligotrophic conditions, acidity and high oxygenation in water is remarked.

Key words: ecology; distribution; rivers and lakes; freshwater Porifera; Douro basin. 
Cómo citar este artículo/Citation: Morales, J. \& Negro, A. I., 2015. Nuevos registros con notas ecológicas y taxonómicas de esponjas dulceacuícolas (Porifera, Spongillidae) en la cuenca del Duero. Grael/sia, 71(1): e021. http://dx.doi.org/10.3989/ graellsia.2015.v71.119.

Copyright: (C) 2015 SAM y CSIC. Salvo indicación contraria, todos los contenidos de la edición electrónica de Graellsia se distribuyen bajo licencia de uso y distribución Creative Commons Reconocimiento no Comercial 3.0. España (cc-by-nc).

\section{Introducción}

El conocimiento actual de la fauna de esponjas de aguas epicontinentales ibéricas es muy pobre. Los trabajos generales sobre biología de las comunidades dulceacuícolas lacustres del NO peninsular de mediados del siglo XX realizados por el Dr. Ramón Margalef representan los datos de referencia más antiguos en cuanto a citas de esponjas dulceacuícolas en España (Margalef, 1955). Únicamente los trabajos de Traveset (1986, 1991) y Uriz (1986) desarrollan algunos aspectos taxonómicos y biométricos de las espículas sobre este grupo zoológico en ríos españoles. A pesar de la perdurabilidad de sus escleras silíceas este grupo zoológico ha sido mucho menos estudiado que otros en ambientes epicontinentales. Por otro lado, tampoco se conocen datos de estudios paleolimnológicos realizados en humedales profundos ya que se centran por lo general sobre polen, esporas o frústulos de diatomeas; y más raramente en quironómidos.

Más recientemente Pronzato \& Manconi (2001) y Manconi \& Pronzato (2002) recogen citas de esponjas dulceacuícolas en ámbito ibérico, y citan de manera imprecisa la presencia de Ephydatia fluviatilis y de Heteromeyenia baileyi en la parte final del curso del Duero en Portugal. Por su parte González \& Cobo (2006) recogen los datos de Margalef (1955) de presencia de $H$. baileyi y citan $E$. fluviatilis en aguas de Galicia próximas a la vertiente septentrional de Sierra Segundera.

El presente trabajo recoge datos recogidos a lo largo de más de una década de muestreos y representa la primera contribución al conocimiento de este grupo zoológico en cauces de la cuenca del Duero, si bien no se corresponde con un trabajo sistematizado de prospección en toda su extensión, ya que ha sido dirigido únicamente sobre una serie de ecosistemas permanentes de su mitad occidental.

\section{Material y métodos}

Las muestras de esponjas vivas fueron recogidas en sucesivas campañas de trabajo en las subcuencas fluviales del Duero situadas en la parte más occidental de Castilla y León (Fig. 1). Se realizaron 32 muestreos expresamente dirigidos a su localización durante el estiaje. En los ríos mediante transectos a pie por dentro del agua revisando los sustratos sumergidos de las orillas del cauce de aguas bajas, y en los humedales recorriendo su perímetro durante la época estival. En cada punto de muestreo se inspeccionó una distancia distinta, en función de la heterogeneidad de las orillas. El hallazgo de esponjas se realizó en tramos fluviales vadeables (25 muestreos) y en el litoral de lagunas profundas (7 muestreos), mediante inspección visual en lugares muy someros y mediante la ayuda de batiscopio con fondo de vidrio.

Se aportan registros de las subcuencas de los ríos Tera, Negro y Aliste en el noroeste de Zamora, Eria en el nordeste zamorano, Águeda y Huebra en el suroeste y Tormes en el sureste de Salamanca, y por último en las del Omañas y Luna en el noroeste y del Eria en el sur de León (Fig. 1). Todas las estaciones de muestreo (9 en el Tera, 3 en el Negro, 2 en el Águeda y una en el resto de localidades) están ubicadas en cauces permanente de tramos de cabecera próximos a las zonas montañosas de la orla periférica de la meseta norte, y con un estado de conservación aceptable que ha permitido su inclusión en Natura 2000. Se trata en todos los casos de ríos con escasa mineralización, ya que dichos cauces discurren predominantemente por sustratos poco solubles de granitos, gneises, pizarras y cuarcitas. Los datos de calidad del agua que se utilizan pertenecen a las redes oficiales de seguimiento de Confederación Hidrográfica del Duero (CHD) y representan los valores promedio anual de la estación en el periodo 2008-2010.

Las muestras fueron tomadas manualmente recogiendo una parte de la estructura de la esponja pegada al sustrato. Las determinaciones se hicieron con microscopía óptica y electrónica, a través de morfología de las espículas (macro y microscleras) del citoesqueleto (presentes casi todo el año en tejidos de crecimiento y cuerpos de reducción), y de las gemoscleras presentes únicamente en época estival (estructura esquelética de las gémulas vegetativas) (Fig. 2). Se utilizará la terminología incluida en Uriz (1986) para la denominación de las espículas, y siguiendo las consideraciones de Pronzato \& Manconi (2001) estas estructuras fueron observadas al microscopio tras un proceso de limpieza para eliminar la materia orgánica procedente de la espongina y los organismos simbiontes. Se mantuvieron entre 48 y 72 horas sumergidas en ácido nítrico $65 \%$ a temperatura ambiente, y posteriormente se sometieron a un proceso de sucesivos lavados con peróxido de hidrógeno durante otros 4 días más. Posteriormente fueron lavadas varias veces con agua destilada, y finalmente almacenadas en etanol de $70^{\circ}$.

Las medidas biométricas de espículas (con precisión de $0,1 \mu \mathrm{m}$ ) se hicieron al microscopio óptico (MO) con un equipo invertido Nikon Eclipse-Ti y software NIS-Elements. Se utilizó también un microscopio 


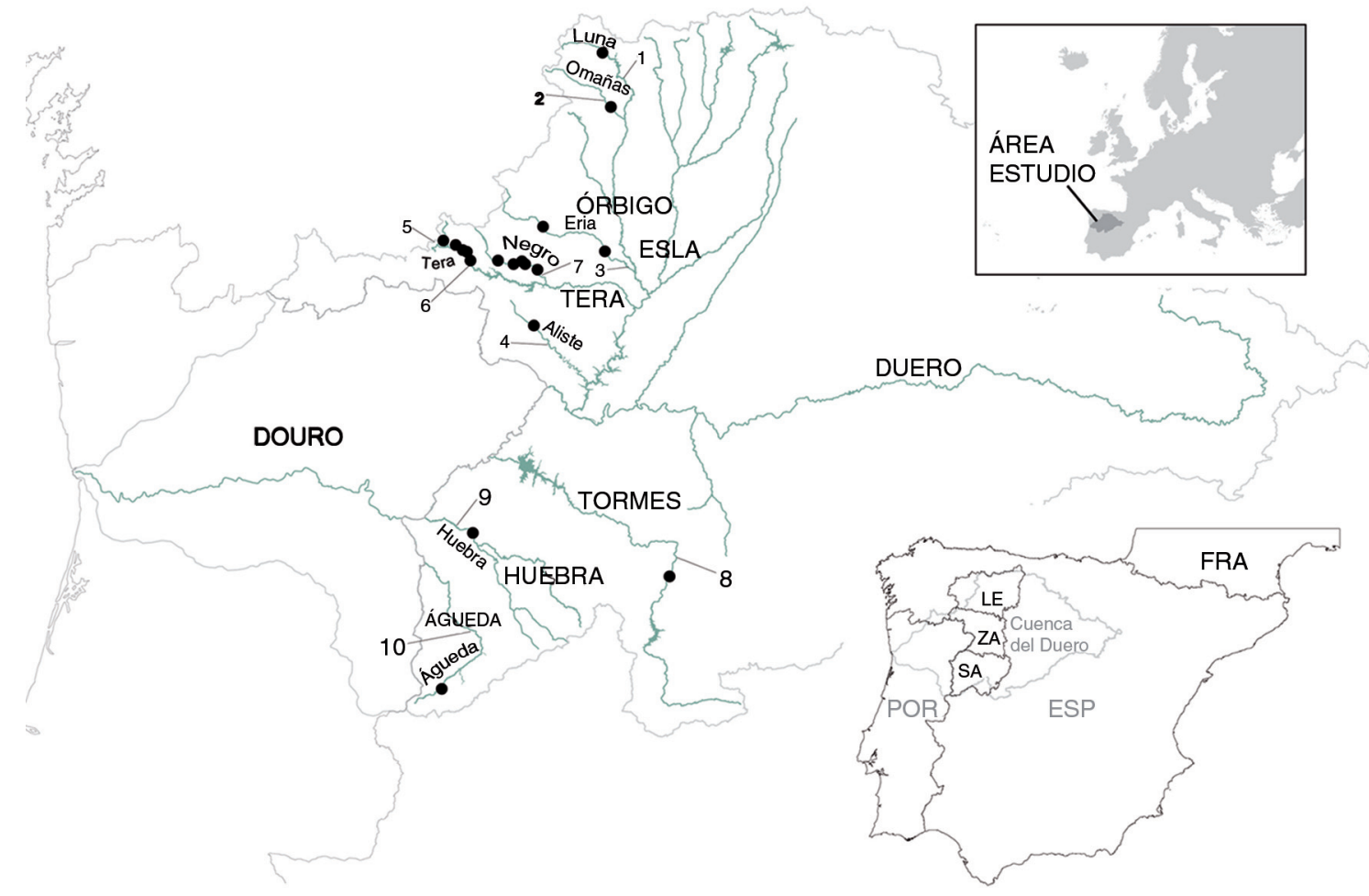

Fig. 1.- Localización de los tramos de las subcuencas fluviales en las que se estudiaron las esponjas, tipos de masas de agua y ubicación y red a la que pertenecen las estaciones de seguimiento de la calidad del agua (www.chduero.es) utilizadas (referencia en Tabla 1).

Fig. 1.- Location of the sample points in the river sub-basins studied, water body types and location of CHD water quality monitoring stations (reference in Table 1). Contours provinces of León (LE), Zamora (ZA) and Salamanca (SA) are shown on the international Douro-Duero watershed.

electrónico de barrido (SEM) EVO-Zeiss para poder afinar más en los caracteres taxonómicos de las espículas e ilustrar su morfología en detalle. Para lo cual las muestras limpias se prepararon sobre un portaobjetos de vidrio utilizando un alícuota en suspensión acuosa, que se dejó secar lentamente a temperatura ambiente y se le aplicó metalización con oro.

La determinación visual se hizo utilizando las ilustraciones y microfotografías de escleras incluidas en las claves taxonómicas de Potts (1887), Traveset (1986, 1991), Uriz (1986), Frost et al. (2001) y Pronzato \& Manconi (2001); y algunos otros trabajos que incluyen datos taxonómicos de estas especies como Stephens (1912), Mildner (1995), Økland \& Økland (1996), Manconi \& Pronzato (2002), Roovere et al. (2006), Schletterer \& Eggers (2006) y Dröscher $\&$ Waringer (2007). Se utilizará la nomenclatura taxonómica indicada en el Atlas Europeo de esponjas dulceacuícolas (Pronzato \& Manconi, 2001).

\section{Resultados}

Se han hallado en la parte de la demarcación del Duero en la que se ha trabajado cuatro de las seis especies citadas para la Península Ibérica en la monografía de Traveset (1986), única referencia hasta la actualidad sobre la fauna dulceacuícola de poríferos en este ámbito. Todas pertenecientes a la Clase Demospongiae Sollas, 1885, Familia Spongillidae Gray, 1867 (Tabla 1). Se obtuvieron datos de distribución de esponjas en 24 ocasiones (16 localidades). Los datos de localización de los ejemplares, las fechas de las citas y algunas notas de la biología y ecología básica de cada especie y su encuadre taxonómico se detallan en los siguientes apartados.

Ephydatia fluviatilis (Linnaeus, 1759)

(Figs. 3, 8F-H, 9F-H)

Se han obtenido 9 citas de esta especie repartidas en 5 ríos. Ha sido encontrada en las siguientes localidades y fechas:

ZA: río Tera (29/09/2001, 14/06/2005) [UTM: 29T PG 693E 4664N, z: $948 \mathrm{msm}$ ], (15/09/2012) [UTM: 29T PG 694E 4663N, z: $946 \mathrm{msm}$ ]; río Negro (29/09/2001) [UTM: 29T PG 714E 4659N, z: $892 \mathrm{msm}$ ], (31/08/2005) [UTM: 29T PG 719E 4660N, z: $862 \mathrm{msm}]$; río Eria (14/08/2011) [UTM: 30T PG 257E 4672N, z: $789 \mathrm{msm}$ ]

LE: río Luna (04/09/2012) [UTM: 30T PG 258E 4756N, z: $1.117 \mathrm{msm}$ ]; (04/10/2013) [UTM: 29T QG 254E 7974N, z: $986 \mathrm{msm}]$

SA: río Huebra (29/05/2010) [UTM: 29T QF 051E 4540N, z: $625 \mathrm{msm}$ ] 

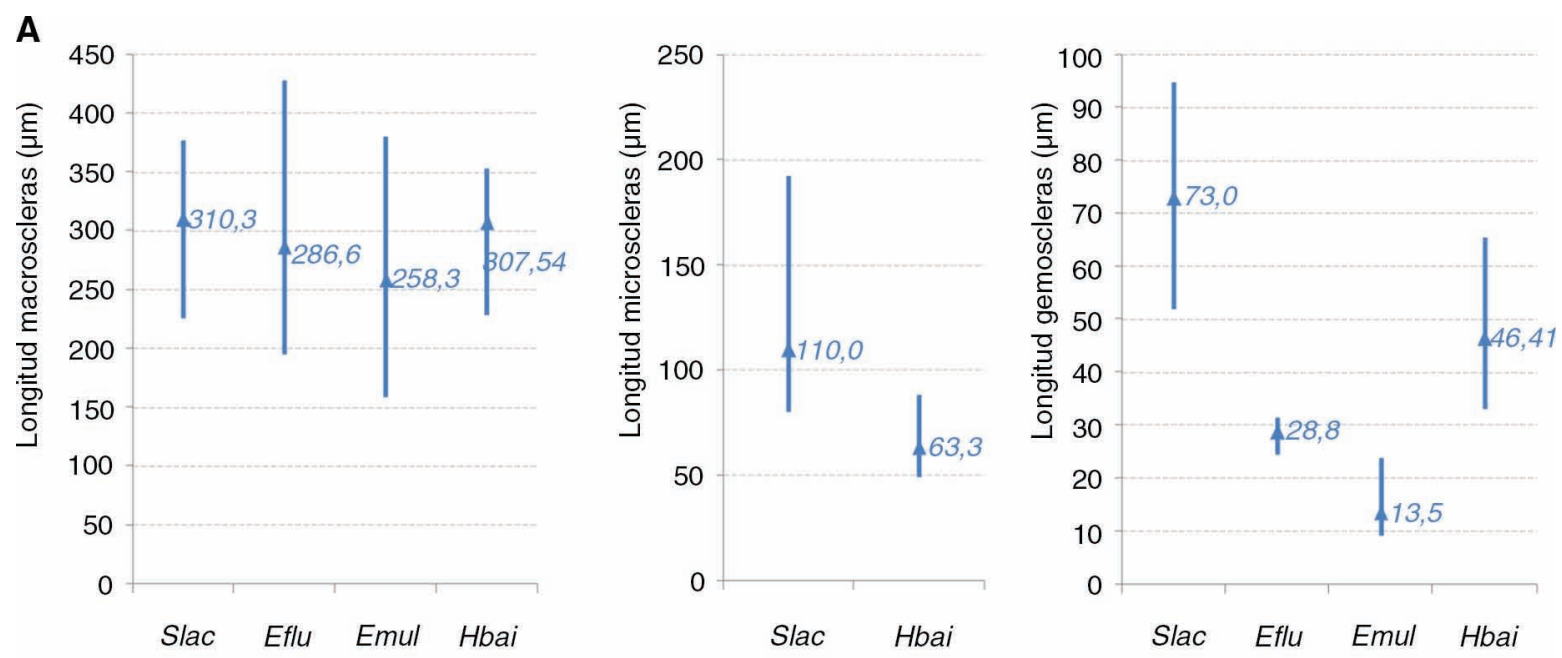

B

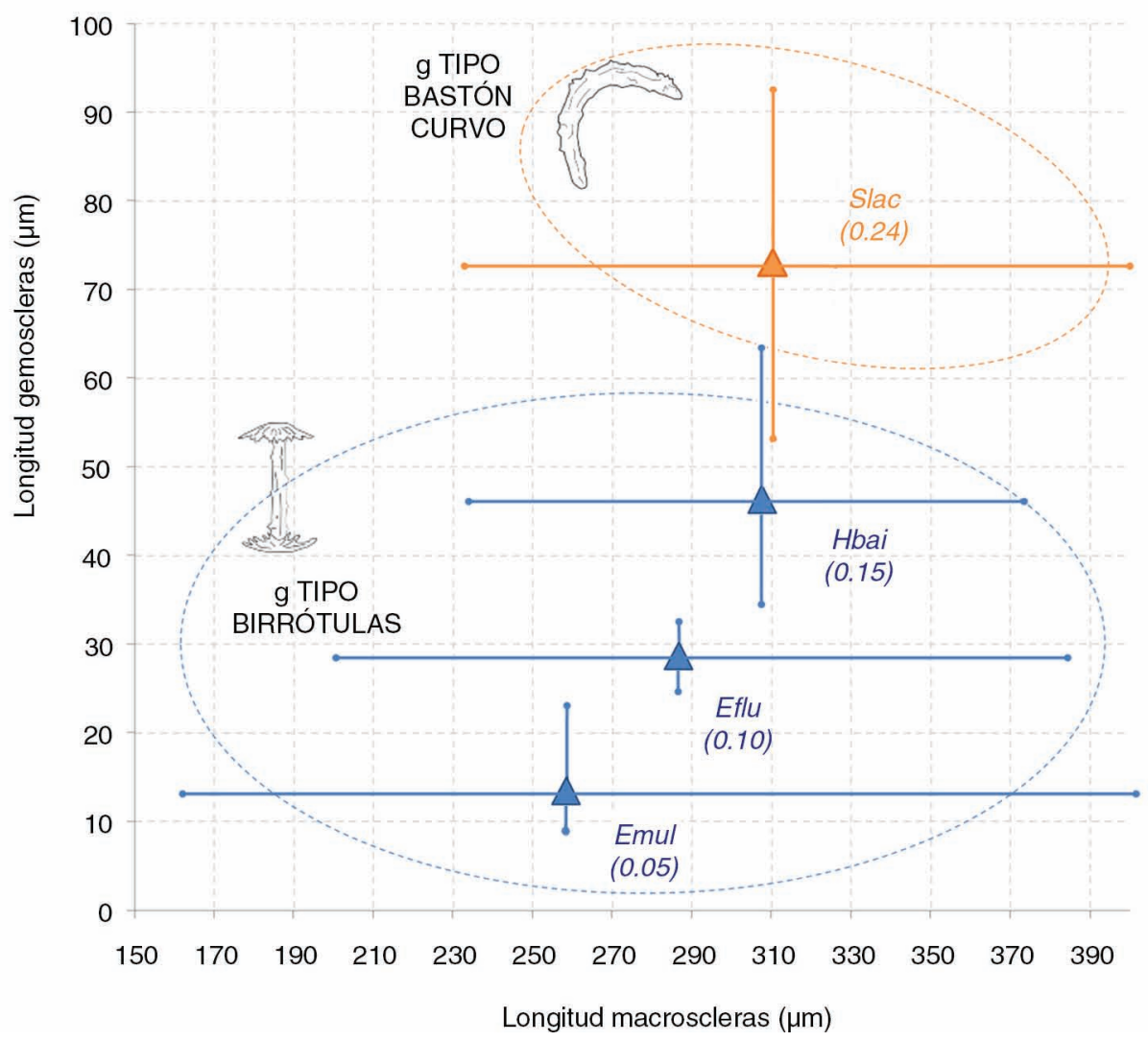

Fig. 2.- A) Descriptiva básica de la longitud media aritmética y rango de variación (máximo-mínimo) de la longitud de los tres tipos de espículas. B) Relación entre la longitud promedio de las macro y gemoscleras para las especies de la cuenca del Duero; se indica el cociente g/M para cada especie entre paréntesis. Abreviaturas como en Tabla 2.

Fig. 2.- A) Descriptive average length and range (max-min) of the different types of sclera. B) Relationship between the average length of the macro and gemoscleras for Duero Basin species; ratio g/M in brackets. Abbreviations as in Table 2.

E. fluviatilis se ha localizado con exclusividad sobre sustratos pétreos, en general grandes bloques y roca madre en el borde de los cauces, formando grandes masas celulares con un cierto espesor, así como con un aspecto más conspicuo de los ósculos y los canales somáticos. Sólo en una de las ocasiones las esponjas presentaban microbios verdes simbiontes dentro de su estructura corporal, que no fueron identificados. Los ejemplares localizados eran predominantemente de morfotipo incrustante, y en menor frecuencia de tipo masivo; no se han encontrado ejemplares con morfología de tipo arborescente.

Las macroscleras de tipo diactina-oxa presentaron una longitud promedio en torno a $287 \mu \mathrm{m}$ con aspecto 
Tabla 1.- Encuadre hidrográfico de los ecosistemas, estación referencia para los datos de calidad del agua (Fig. 1) y presencia (+) de las cuatro especies de poriferos dulceacuícolas.

Table 1.- Ecosystems hydrographic framing, reference data station for water quality (Fig. 1) and presence (+) of the four species of freshwater sponges.

\begin{tabular}{|c|c|c|c|c|c|c|c|}
\hline Subcuenca & Río o humedal & ${ }^{*}$ Ecotipo & $\begin{array}{l}\text { Ephydatia } \\
\text { fluviatilis } \\
\text { (Eflu) }\end{array}$ & $\begin{array}{c}\text { Ephydatia } \\
\text { muelleri } \\
\text { (Emue) }\end{array}$ & $\begin{array}{c}\text { Heteromeyenia } \\
\text { baileyi (Hbai) }\end{array}$ & $\begin{array}{l}\text { Spongilla } \\
\text { lacustris } \\
\text { (Slac) }\end{array}$ & $\begin{array}{c}\text { Estación CHD de } \\
\text { referencia (referencia } \\
\text { en figura 1) }\end{array}$ \\
\hline \multirow[t]{3}{*}{ Órbigo } & Luna & 25 & + & & & & (1) La Magdalena \\
\hline & Omañas & 25 & & & & + & (2) Omañas \\
\hline & Eria & 25 & + & & & & (3) Morales del Rey \\
\hline Esla & Aliste & 3 & & + & & & (4) Domez \\
\hline \multirow[t]{4}{*}{ Tera } & Lagunas glaciares & 03 & & & & + & (5) Embalse de Cárdenas \\
\hline & Alto Tera & 27 & & & & + & \\
\hline & Medio Tera & 25 & + & & + & + & (6) Puebla de Sanabria \\
\hline & Negro & 25 & + & & + & + & (7) Rionegro del Puente \\
\hline Tormes & Tormes & 15 & & & + & & (8) Encinas de Arriba \\
\hline Huebra & Huebra & 15 & + & & & & (9) Cerralbo \\
\hline Águeda & Águeda & 11 & & & + & & (10) Ciudad Rodrigo \\
\hline
\end{tabular}

* Ecotipos según el Anexo II de la Directiva Marco del Agua / FWD Anex II ecotype

03: humedales monomícticos de montañas ácidas / northern high mountain monomictic \& acidic lakes

3: ríos silíceos de llanura de la Meseta Norte / plate siliceous rivers of the Northern Plateau

11: ríos de montaña silícea mediterránea / siliceous Mediterranean mountain rivers

15: grandes ejes continentales mediterráneos / Mediterranean continental axes slightly mineralized

25: ríos de montaña húmeda silícea / siliceous wet mountain rivers

27: ríos de alta montaña / high mountain rivers

algo curvado y de superficie totalmente lisa. En los 7 ejemplares en los que se realizó análisis microscópico se encontraron gémulas. Las gemoscleras son de tipo anfidisco birrótula y de pequeño tamaño (Tabla 1), aunque con un eje mucho mayor que en el caso de E. muelleri. Se realizaron medidas para un conjunto de 118 espículas de individuos recogidos en los ríos Tera, Negro, Eria, Luna y Huebra; y su estadística descriptiva básica se presenta en la Tabla 2.

Ephydatia muelleri (Lieberkühn, 1856)

(Figs. 4, 8I, 9I-J)

La especie ha sido encontrada en una única localidad del río Aliste:

\section{ZA: río Aliste (23/06/2013) [UTM: 29T QG 722E 4635N, z: $783 \mathrm{msm}]$}

Pronzato y Manconi (2001) no recogen la presencia de esta especie en el NO ibérico, y no se conocen datos antiguos de presencia de esta especie en el Duero. Únicamente se ha localizado un ejemplar sobre madera sumergida y raíces en la aliseda del río Aliste, formando pequeñas masas celulares muy híspidas de color marrón verdoso de poco espesor sobre el sustrato.

Se realizaron medidas en un total de 85 espículas procedentes de un único individuo capturado en junio de 2013 y que presentaba gémulas. Entre las macroscleras de tipo diactina se encontraron dos morfotipos, uno liso (tornote) y más fino (tipo 1, en Tabla 1: promedio de unos $258 \mu \mathrm{m}$ ), mientras que otras de superficie dentada (tipo 2, acantoxa) que presentaron un tamaño promedio de casi $296 \mu \mathrm{m}$. Las gemoscleras son de tipo anfidisco birrótula y de dimensiones muy pequeñas (Tabla 2), mucho menores que en el caso de E. fluviatilis.

Heteromeyenia baileyi (Bowerbank, 1863) (Figs. 5, 8D-E)

Se han obtenido 6 citas repartidas en 4 ríos. Esta especie ha sido encontrada en las siguientes localidades y fechas:

ZA: río Negro (14/06/2001, 29/09/2001) [UTM: 29T PG 714E 4659N, z: $892 \mathrm{msm}$ ], (16/09/2009) [UTM: 29T PG 7242E 4660N, z: $835 \mathrm{msm}$ ]; río Tera (15/09/2012) [UTM: 29T PG 695E 4660N, z: $909 \mathrm{msm}]$

SA: río Águeda (07/07/2010) [UTM: 29T PG 696E 4469N, z: $790 \mathrm{msm}$; ; azud de Villagonzalo, río Tormes (04/07/2009) [UTM: 30T PG 288E 4523N, z: $810 \mathrm{msm}]$

Únicamente se ha localizado sobre bloques y gravas gordas en el lecho de los ríos, en general formando pequeñas masas celulares muy finas. En todos los casos las esponjas localizadas por nosotros presentaron un característico tono verde intenso y morfotipo incrustante.

Las macroscleras son de tipo diactina-oxa y presentaron una talla mediana de casi $308 \mu \mathrm{m}$. Las microscleras, de tipo diactina-acantoxa y aspecto 
A



C



E

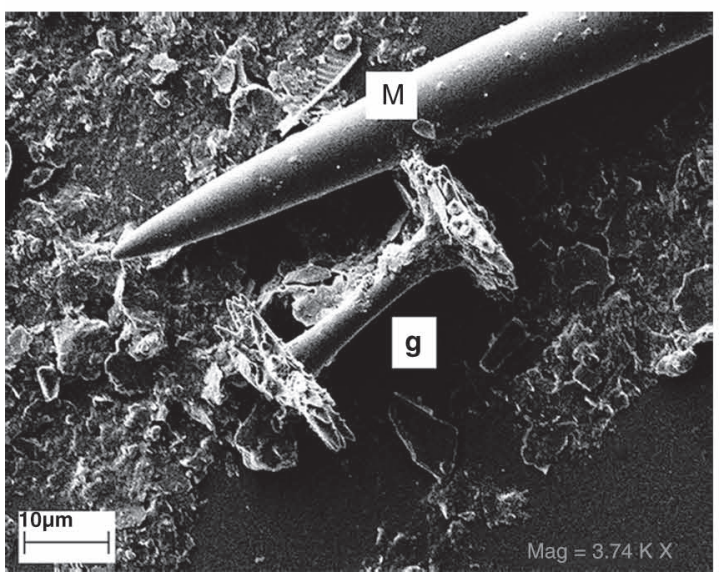

B

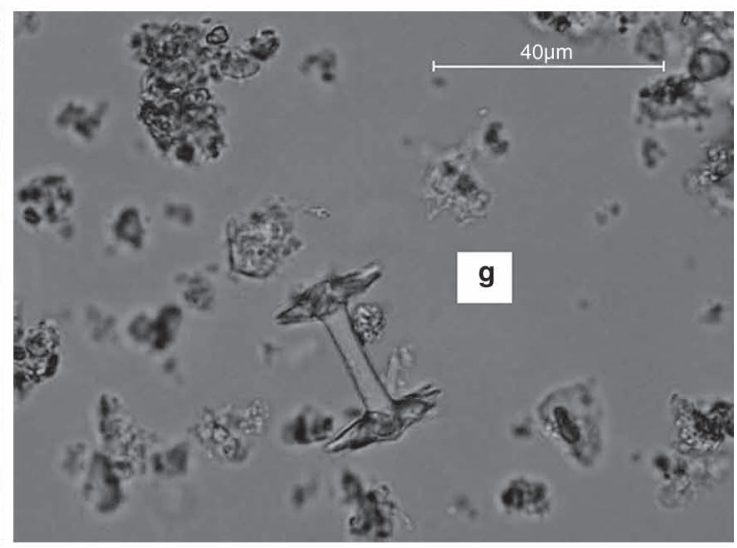

D



$\mathbf{F}$

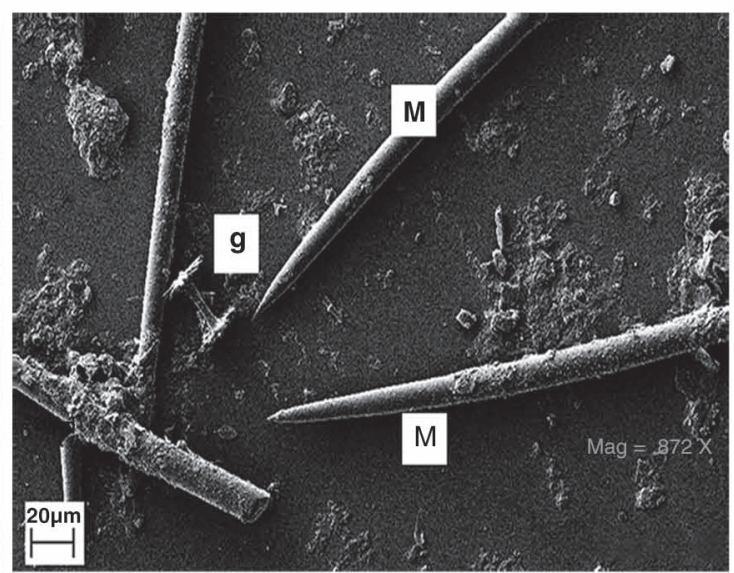

Fig. 3.- Imágenes de escleras del MO (A-D) y SEM (E-F) de E. fluviatilis y una gémula (A). Abreviaturas como en Tabla 2.

Fig. 3.- OM (A-D) and SEM (E-F) microphotographs of E. fluviatilis sclera and gemmule (A). Abbreviations as in Table 2.

superficial fuertemente espinoso, midieron en promedio unas $63 \mu \mathrm{m}$ (Fig. 2). En 2 de los ejemplares 3 en los que se realizó este análisis biométrico se encontraron gemoscleras. Las gemoscleras son de tipo anfidisco birrótula y presentaron un tamaño promedio de casi $29 \mu \mathrm{m}$; el diámetro del eje central y el de la cabeza fue de 3.6 y $21.4 \mu \mathrm{m}$, respectivamente. Se realizaron medidas sobre un total de 177 espículas procedentes de dos individuos (Tabla 2), uno del Tera y otro del Águeda.
Spongilla lacustris (Linnaeus, 1759)

(Figs. 6, 8A-C, 9A-E)

Se han obtenido 18 citas repartidas en 3 ríos y varios ecosistemas lacustres de altitud. La especie ha sido encontrada en las siguientes localidades y fechas:

ZA: lago de Sanabria, (14/06/2001, 29/09/2001) [UTM: 29T PG 687E 4665N, z: $998 \mathrm{msm}$ ]; (16/08/2002) [UTM: 29T PG 687E 4666N, z: 998 msm], (23/04/2011) [UTM: 29T 
Tabla 2.- Estadística descriptiva básica (rango: mediana \pm desviación típica) de las siguientes medidas (en micras) biométricas: longitud (I) y anchura (a) de espículas, diámetro de gémula (d), diámetro del foramen (f) de la gémula. (n: tamaño muestral; -: sin datos *: M de tipo 1, **: tipo 2).

Table 2.- Basic descriptive (mean \pm standard deviation) of the scleres and gemmules biometric ranges (in microns) (I: length,: a: width, d: gemmular and f: foramen diameter). (n: sample size, -: no data, *: M type 1, **: type 2).

\begin{tabular}{|c|c|c|c|c|c|c|c|c|c|c|c|c|}
\hline & \multicolumn{9}{|c|}{ Espículas } & \multicolumn{3}{|c|}{ Gémulas (G) } \\
\hline & \multicolumn{3}{|c|}{ macroescleras $(\mathrm{M})$} & \multicolumn{3}{|c|}{ microescleras (m) } & \multicolumn{3}{|c|}{ gemoescleras (g) } & \multirow[b]{2}{*}{$\mathbf{n}$} & \multirow[b]{2}{*}{ d } & \multirow[b]{2}{*}{$\mathbf{f}$} \\
\hline & $n$ & I & a & $n$ & I & $\bar{a}$ & $n$ & I & a & & & \\
\hline Eflu & 83 & $286.6 \pm 38.1$ & $9.45 \pm 1.27$ & & & & 35 & $28.8 \pm 1.9$ & $22.0 \pm 1.7$ & - & - & - \\
\hline \multirow[t]{2}{*}{ Emue } & $40^{*}$ & $259.4 \pm 48.5$ & $19.51 \pm 2.8$ & & & & 63 & $13.2 \pm 2.8$ & $21.3 \pm 2.0$ & - & - & - \\
\hline & $45^{\star \star}$ & $290.5 \pm 35.1$ & & & & & & & & & & \\
\hline Hbai & 22 & $307.5 \pm 38.5$ & - & 78 & $63.3 \pm 7.7$ & - & 74 & $46.4 \pm 8.1$ & $17.9 \pm 1.1$ & - & - & - \\
\hline Slac & 102 & $311.2 \pm 32.2$ & $11.4 \pm 3.7$ & 111 & $108.0 \pm 16.8$ & - & 17 & 74.9 & 11.6 & 8 & $467.2 \pm 56.9$ & $51.36 \pm 3.4$ \\
\hline
\end{tabular}

PG 689E 4665N, z: $998 \mathrm{msm}]$; río Tera $(29 / 09 / 2001$, 16/08/2002, 14/06/2005) [UTM: 29T PG 693E 4664N, z: $948 \mathrm{msm}$ ], (06/09/14) [UTM: 29T PG 691E $4665 \mathrm{~N}, \mathrm{z}$ : $975 \mathrm{msm}],(29 / 07 / 2011,14 / 06 / 2014)$ [UTM: 29T PG 684E $4669 \mathrm{~N}, \mathrm{z:} 1.349 \mathrm{msm}]$; laguna de Lacillo $(05 / 09 / 2001$, 27/08/2008, 01/10/2008, 05/08/2013) [UTM: 29T PG 682E 4674N, z: $1.705 \mathrm{msm}$ ]; laguna del Cuadro (05/09/2001, 27/08/2008) [UTM: 29T PG 683E 4668N, z: $1.629 \mathrm{msm}$ ]; río Negro (14/06/2001) [UTM: 29T PG $714 \mathrm{E} 4659 \mathrm{~N}, \mathrm{z}$ : $892 \mathrm{msm}$ ]

LE: río Omañas (05/09/2012) [UTM: 30T PG 262E 4731N, z: $957 \mathrm{msm}]$

S. lacustris se ha encontrado tanto sobre sustratos naturales duros (pétreos y madera) como artificiales (pilastras de puentes y azudes tradicionales); y el caso de zonas profundas (-z: $>6 \mathrm{~m})$ de los humedales de Sanabria también sobre sedimentos finos. En el caso de los ríos se localizó con preferencia en zonas de pozas profundas (-z: $>1.5 \mathrm{~m})$, y también en elementos sumergidos en las orillas. Es la única especie encontrada en lagunas de alta montaña, y también la única localizada en la zona afótica del lago de Sanabria. Asimismo es la única de la que se han encontrado al final de verano ejemplares con morfotipo arborescente, tanto sobre sustratos finos como sobre maderas sumergidas.

Las macroscleras son de tipo diactina-oxa muy poco curvadas y de superficie lisa; presentaron una talla mediana de unas $311 \mu \mathrm{m}$. Las microscleras son de tipo diactina-acantoxa y midieron en promedio unas $110 \mu \mathrm{m}$ (Fig. 2). En 5 ejemplares de los 6 en los que se realizó este análisis biométrico se encontraron gemoscleras. Las gemoscleras son de tipo microacontoxas y presentaron un tamaño promedio de casi $75 \mu \mathrm{m}$. Se realizaron medidas en un total de 262 espículas (Fig. 2) pertenecientes a 6 individuos (Tabla 2) de los ríos Tera, Omañas y laguna de Lacillo. En tan sólo uno de 10 ejemplares analizados se encontraron gémulas, de aspecto apergaminado y color marrón. Éstas presentaron un diámetro promedio superior a $455 \mu \mathrm{m}$.
Aunque todos los medios acuáticos estudiados tienen condiciones oligotróficas y de escasa mineralización se encontraron diferencias entre las comunidades de poríferos en función del $\mathrm{pH}$, la altitud y los contenidos de sales disueltas y sílice en el agua (Fig. 7). $S$. lacustris es la especie que se encontró en un rango altitudinal más amplio (849 m, hasta $1.705 \mathrm{msm}$ en laguna de Lacillo) en 9 localidades (Fig. 7A), 5 de ellas pozas o lagunas de alta montaña; se citó la especie a una altitud promedio de $1133 \pm 339 \mathrm{msm}$. Mientras que H. baileyi únicamente se encontró en un rango de 128 $\mathrm{m}$ en las 4 localidades en las que se cita (Tabla 1), con una altitud promedio de $838 \pm 58 \mathrm{msm}$. S. lacustris y $H$. baileyi son las especies que presentaron alguna relación con la mineralización del agua, con preferencia por ríos ácidos $(\mathrm{pH}<7.2)$, oligohalinos $(<40 \mu \mathrm{S} / \mathrm{cm})$ y de aguas muy blandas $(<20 \mathrm{mg} \mathrm{CaCO} / 1)$, mientras que ambas especies de Ephydatia fueron encontradas en zonas algo más mineralizadas (Fig. 7B). En cuanto al contenido en sílice, el componente estructural de las escleras, del agua no se hallaron diferencias entre las especies estudiadas; encontrándose en rangos superiores a $3 \mathrm{mg} / \mathrm{l}$ en todos los casos.

\section{Discusión}

Se recogen datos obtenidos mediante la búsqueda activa de esponjas en zonas vadeables de ríos y en las cubetas de humedales profundos para recolectar material vivo, a través del cual se ha conseguido citar en los ríos occidentales del Duero a 4 de las 6 especies conocidas en la poriferofauna dulceacuícola ibérica (Traveset, 1986; Pronzato \& Manconi, 2001). La presencia de otras especies citadas en aguas ibéricas no han sido confirmadas en los ecosistemas estudiados del Duero. En concreto, no se ha detectado la presencia de Eunapius fragilis (Leidy, 1851) citada en el Ebro medio (Oscoz et al., 2009; datos propios); ni de Trochospongilla horrida (Weltner, 1893), citada fósil en aguas del Tajo en Portugal por Traveset (1986) y 
A

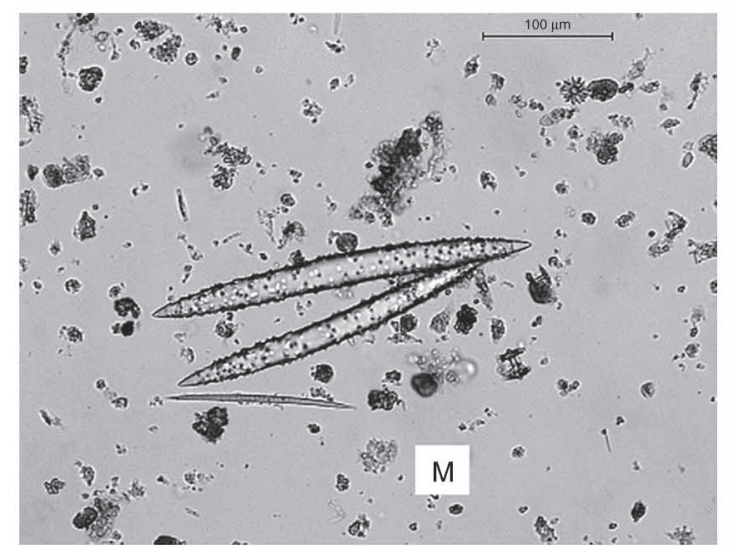

C

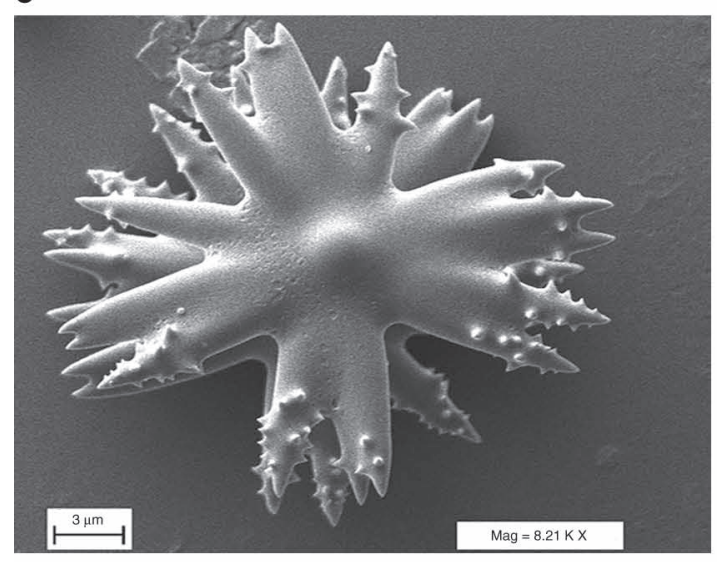

E

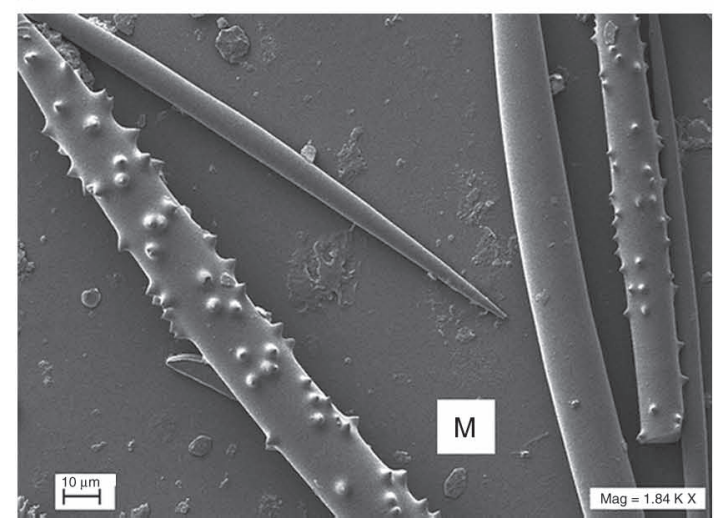

B



D



$\mathbf{F}$

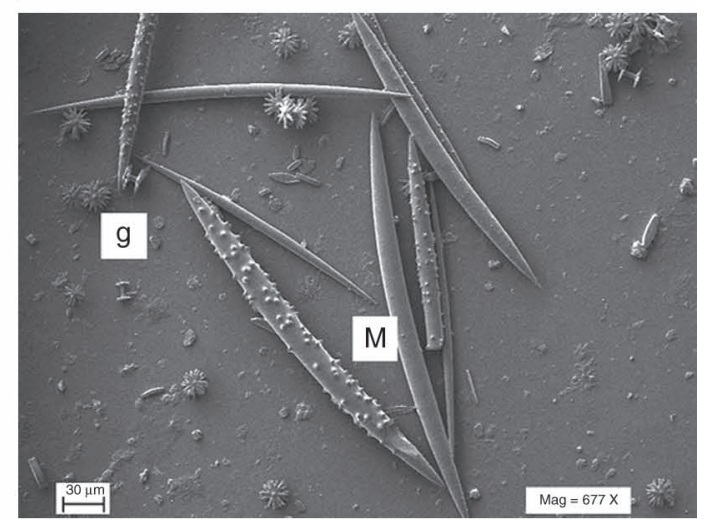

Fig. 4.- Imágenes de escleras del MO (A-D) y SEM (E-F) de E. muelleri. Abreviaturas como en Tabla 2.

Fig. 4.- OM (A-D) and SEM (E-F) microphotographs of E. mulleri sclera. Abbreviations as in Table 2.

Pronzato \& Manconi (2001). Las macroscleras presentaron muy poco valor diagnóstico en la determinación al microscopio ya que los tamaños en las cuatro especies fue muy similar, al igual que su morfología externa. Por el contrario las micro, y sobre todo las gemoscleras, sí poseen morfologías muy diferentes entre las especies y tamaños exclusivos (Fig. 2) como carácter taxonómico valioso.

Spongilla lacustris es el taxón más conocido del grupo, y se trata de una especie ampliamente distribuida por casi toda la región Paleártica (Norteamérica, Eurasia y la India) en zonas con buen estado de conservación. Habita desde humedales de Siberia, en territorios de dominio del permafrost, hasta ríos y lagos mediterráneos templados; así como desde zonas bajas hasta lagunas alpinas de alta montaña. Citas antiguas de esta especie en el NO de la Península Ibérica provienen del amplio trabajo de Margalef (1955) sobre las comunidades dulceacuícolas. En concreto, cita la presencia de S. lacustris var. paupercula en varios 
A



c

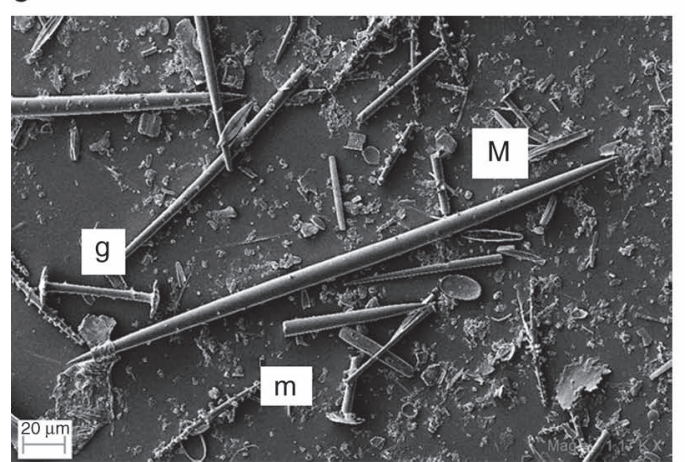

E



B

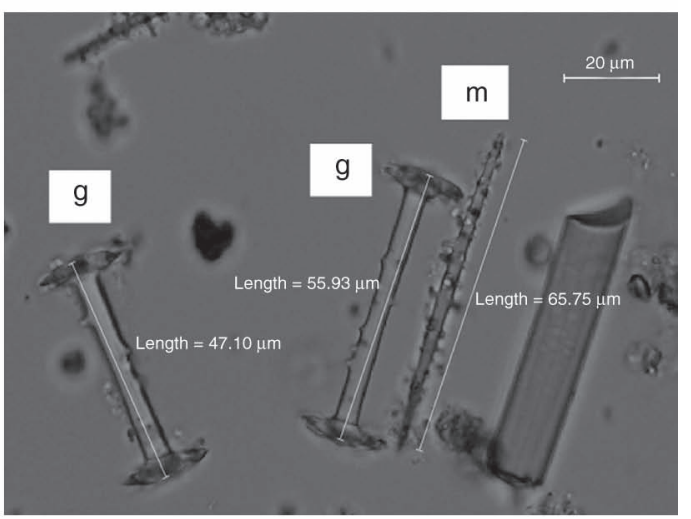

D

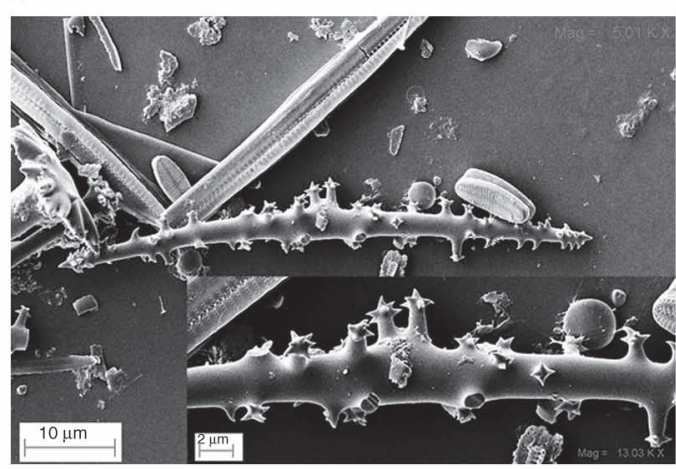

$\mathbf{F}$



Fig. 5. - Imágenes del MO (A-B) y SEM (C-F) de espículas de H. baileyi, y una gémula (A). Abreviaturas como en Tabla 2.

Fig. 5. - OM (A-B) and SEM (C-F) microphotographs of $H$. baileyi sclera and gemmule (A). Abbreviations as in Table 2.

puntos del río Tera, el lago de Sanabria y en dos de las lagunas del complejo glaciar de Sierra Segundera: Lacillo y el Cuadro. Poblaciones que nosotros hemos localizado en el presente trabajo y cuyo estado de conservación y nivel de ocupación del sustrato, aunque parece bueno (datos propios), está aun por evaluar. Se conocen poblaciones de $S$. lacustris con ciclo de vida hibernante como respuesta fenotípica en las zonas frías (Manconi \& Pronzato, 1991, 2002), y que nosotros hemos comprobado únicamente en aguas profundas del Tera y el lago de Sanabria. Coincidiendo con los datos de Økland \& Økland (1996) hemos encontrado esta especie siempre en ecosistemas de aguas distróficas, en transición de oligo a mesotróficas, y con abundante cobertura de esfagnos en las orillas o en la cuenca de influencia de los mismos. Se trata de una especie que con asiduidad obtiene relación simbionte con microbios autotrofos, hecho constatado por nosotros en varias poblaciones del Duero (Fig. 8B, ejemplar del río Tera). Además de microalgas Gernert et al. (2005) encuentran en ejemplares lacustres asiáticos de $S$. lacustris una gran diversidad de bacterias y actinobacterias, entre las que destacan algunos taxones de bacterias fototróficas no del azufre.

Heteromeyenia baileyi es una especie que en la Península Ibérica parece restringida a un ámbito biogeográfico lusitánico por los conocimientos actuales. Originada como reliquia glaciar, que se habría dispersado hacia el norte y el este de Europa después de la última glaciación Würm (Margalef, 1955). No existen 
A



C

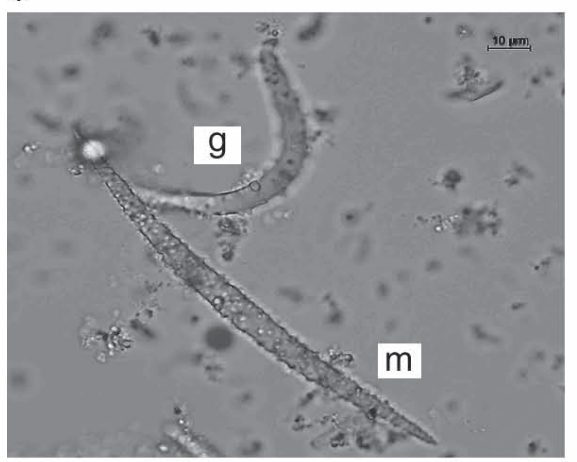

E

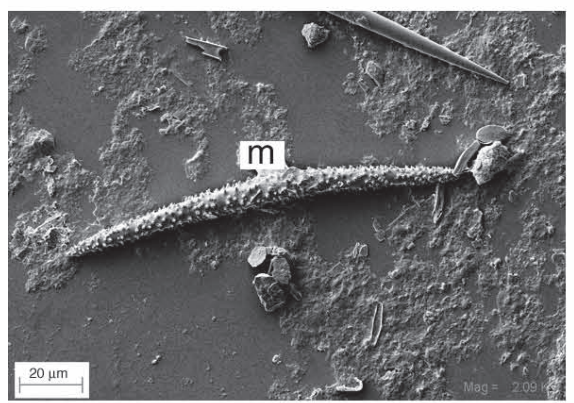

H

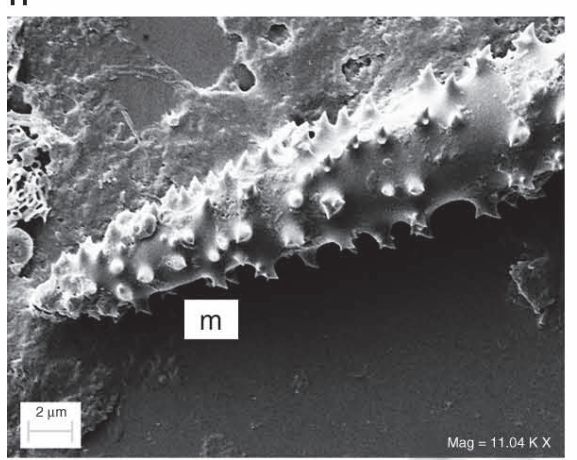

B

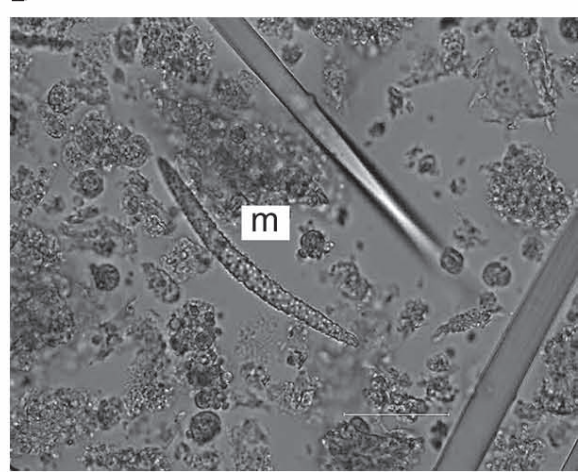

D

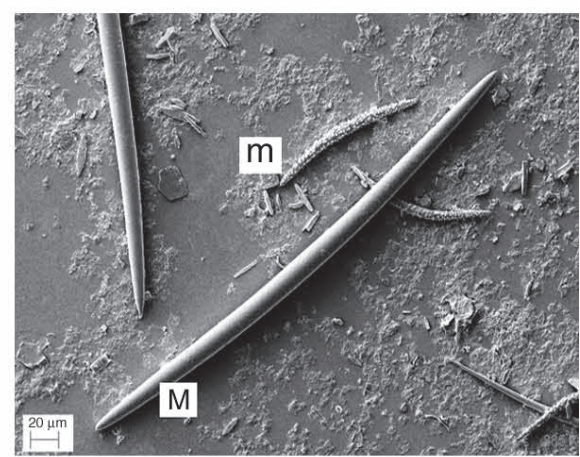

F

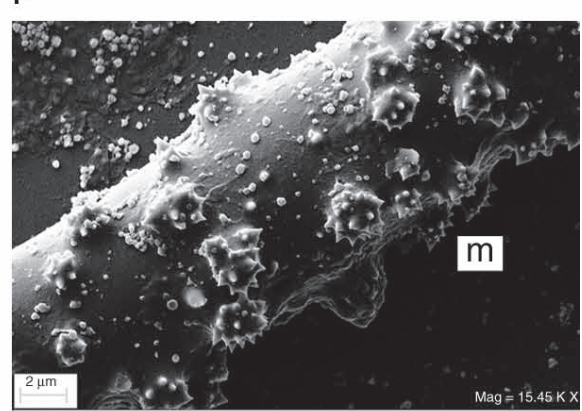

I

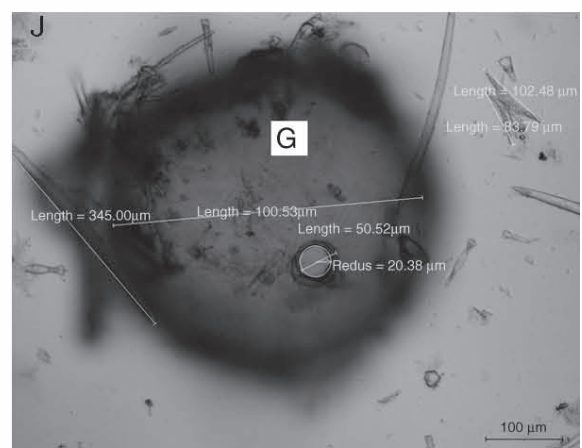

Fig. 6. - Imágenes del MO (A-C) y SEM (D-H) de espículas de S. lacustris y una gémula (J) al MO. Abreviaturas como en Tabla 2. Fig. 6.- OM (A-C) and SEM (D-H) microphotographs of S. lacustris sclera and gemmule (J). Abbreviations as in Table 2.

citas antiguas de la especie en los ríos de la cuenca del Duero. Pronzato \& Manconi (2001) muestran para la especie una corología de tipo disyunta, con un núcleo en el noroeste ibérico y otro en Centroeuropa y Rusia donde comparte ecosistemas con $H$. stepanowii. En hábitats permanentes no suele producir gémulas vegetativas, lo que, junto con su morfología incrustante y poco conspicua, dificulta notablemente su detección. Se trata por lo tanto de una especie capaz de indicar con su presencia niveles de oscilación importantes en el nivel del agua (Simon, 1978 en Traveset, 1986) y que es capaz de sobrevivir a periodos de sequía prolongados (hasta 3-5 años) en forma de gémulas de resistencia (Fig. 8D). Asimismo es una especie que 
A
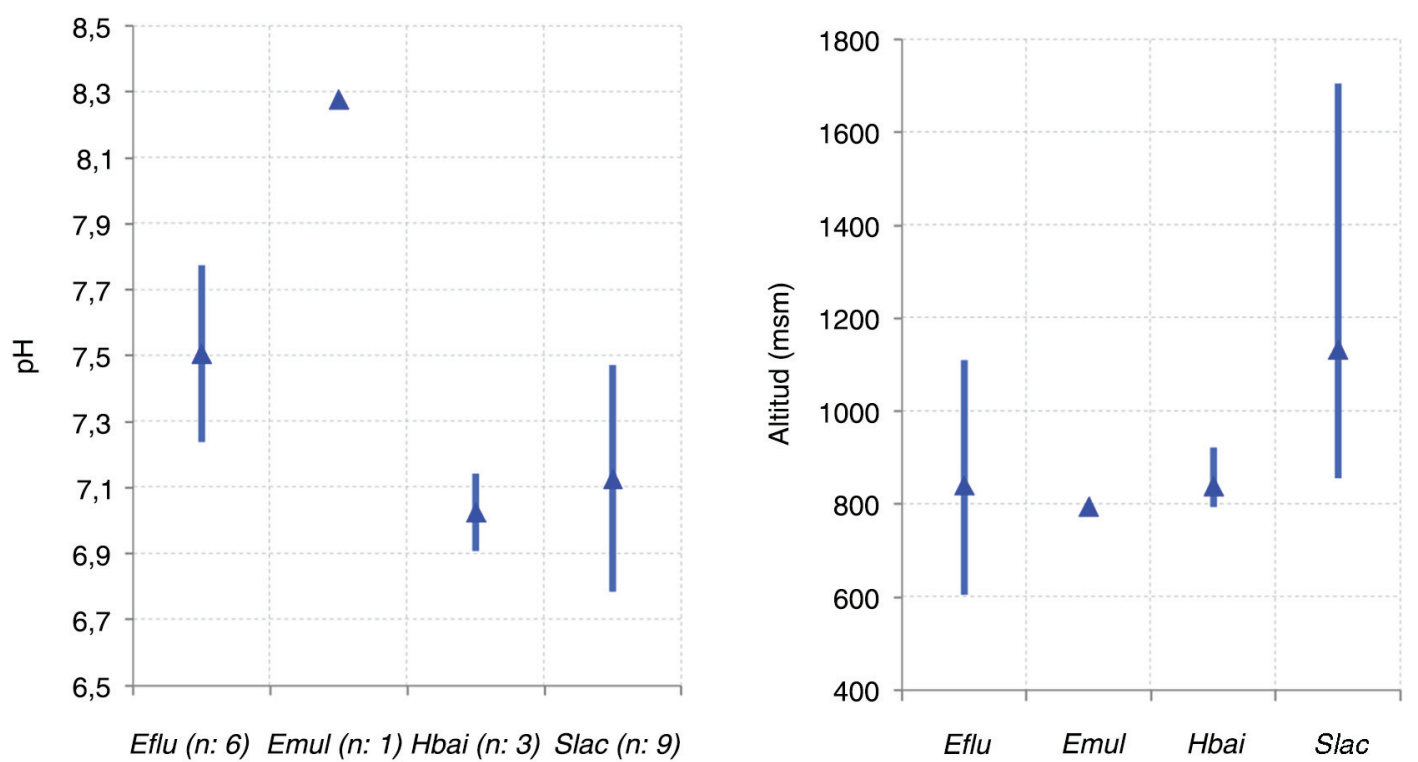

Eflu (n: 6) Emul (n: 1) Hbai (n: 3) Slac (n: 9)

Eflu Emul Hbai Slac

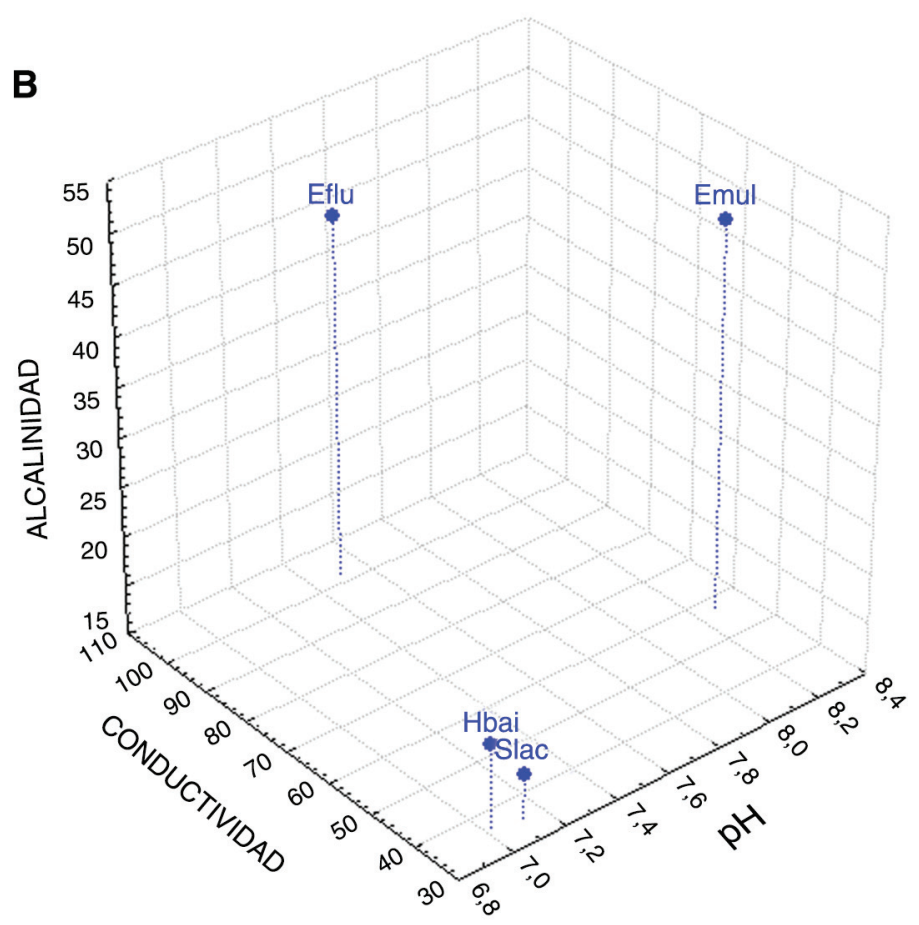

Fig. 7.- Promedio y rangos ocupados por cada especie en cuanto al pH y altitud (A); así como relación (B) de la mineralización del agua con la alcalinidad y el pH para las cuatro especies. Abreviaturas como en Tabla 1, n: número de localidades.

Fig. 7.- Altitude, $\mathrm{pH}$ and water mineralization ranges and means occupied by each species. Abbreviations as in Table 1, n: number of sites.

con asiduidad es simbionte con microbios autotrofos, hecho constatado por nosotros en las poblaciones del Duero (Figs. 8D-E, ejemplar del río Negro).

E. fluviatilis tiene una distribución geográfica sub-cosmopolita (todo el Hemisferio Norte y zonas dispersas del Sur, incluyendo territorios de Oceanía), lo que según Manconi \& Pronzato (2002) podría deberse a ser en realidad un complejo de especies. Se conocen localidades donde la especie hiberna, otras donde estiva y otras donde se mantiene un ciclo vital perenne. Aspecto que refuerza su amplia valencia ecológica, ya que habitan tramos de aguas rápidas y 
A

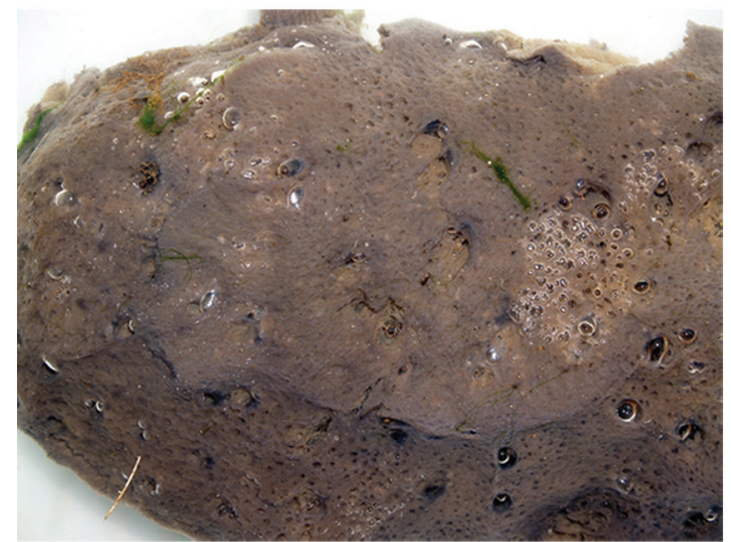

C



E



$\mathrm{H}$

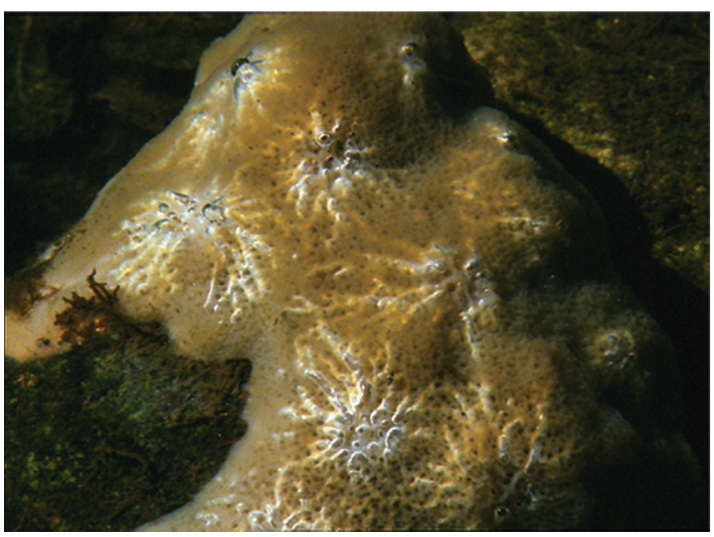

B


F



I



Fig. 8.- Habitus de ejemplares vivos: A-B) S. lacustris del río Negro y Tera, C) del río Tera a $2.5 \mathrm{~m}$ de profundidad (fotografía cedida por José Miguel Uña); D-E) H. bailey del río Negro; F-H) E. fluviatilis del río Tera y Negro; I) E. muelleri del río Aliste. Abreviaturas como en Tabla 2.

Fig. 8.- Live specimens "habitus": A-B) S. lacustris in Negro and Tera rivers, C) in Tera river at $2.5 \mathrm{~m}$ deep (®José Miguel Uña); D-E) H. bailey in Negro river; F-H) E. fluviatilis in Tera and Negro rivers; I) E. muelleri in Aliste river. Abbreviations as in Table 2. 
A

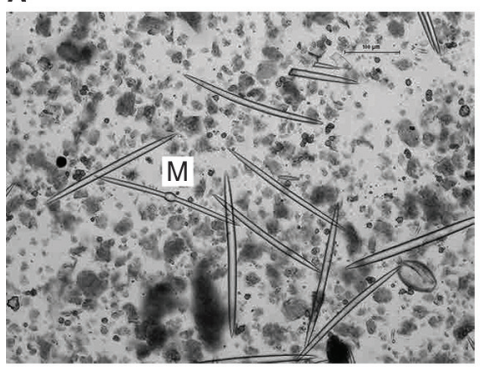

D
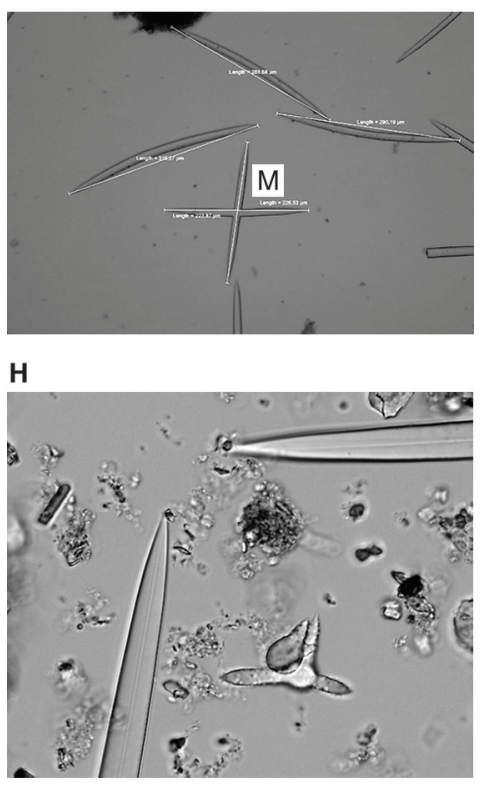

K



B

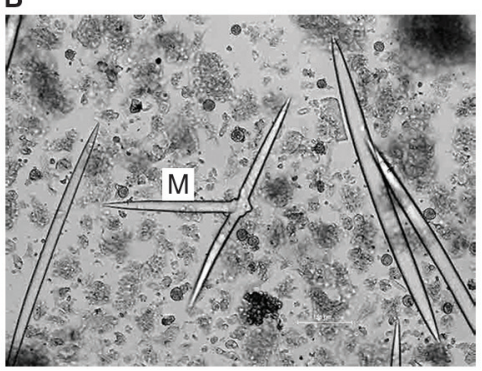

E



I



C

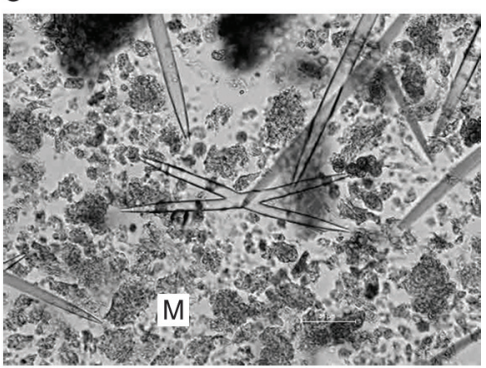

$\mathbf{F}$

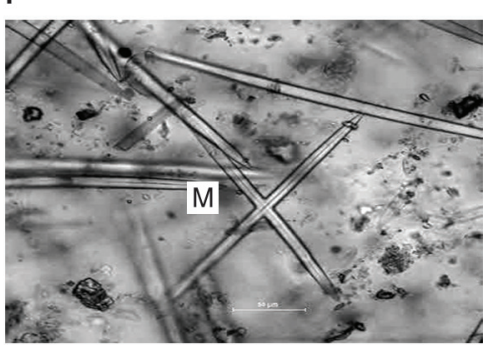

$\mathbf{J}$

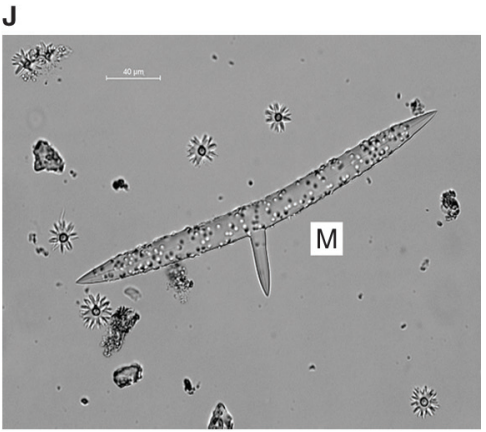

Fig. 9.- Imágenes del MO de escleras con morfología atípica: A-D) macro y E) micro de S. lacustris; F) macro y H-I) escleras no identificadas de E. fluviatilis; J-K) macro de E. muelleri.

Fig. 9.- OM microphotographs of scleras with atypical morphology: A-E) S. lacustris; H-I) E. fluviatilis; J-K) E. muelleri.

quietas, dulces y salobres; así como desde humedales costeros a lagunas alpinas. No se conocen datos antiguos de presencia de esta especie en el Duero; Gil Quilez (1986) documenta su presencia en sedimentos miocénicos de la cabecera del Turia, en la provincia de Teruel. Økland \& Økland (1996) sitúan a esta especie como típica de aguas de carácter mesotrófico, e incluso de lugares eutróficos, y con mayor tendencia a seleccionar tramos de ríos sobre lagunas y lagos profundos con orillas cubiertas por esfagnos. Es una especie que parece tener cierta tolerancia a vertidos orgánicos en las proximidades de pequeñas poblaciones humanas con depuración deficiente (obs. propia). En las lagunas de altitud y el lago de Sanabria esta especie no ha sido hallada, de manera que esto podría ser diagnóstico de un cierto nivel constante de oligotrofia y transparencia en sus aguas.

Según Gugel (2001), E. muelleri es una especie típica de desarrollo rápido en época primaveral en ríos centroeuropeos, lo que le permite utilizar los mismos sustratos en simpatría funcional con otras especies de desarrollo estival como E. fluviatilis y S. lacustris. El único ejemplar localizado en la cuenca del Duero presentaba 2 tipos de macroescleras, con ornamentación 
de superficie y tamaño claramente diferenciados. Aspecto que no ha podido ser explicado. Poirrier (1974) encuentra variaciones morfológicas sin reflejo taxonómico en las escleras de E. fluviatilis en cautividad inducidas por variaciones del $\mathrm{pH}$ en el agua. En la Figura 9 se presenta una galería de diseños irregulares, en forma y tamaño, para micro y macroescleras de las especies del Duero.

Ambas especies de Ephydatia mostraron preferencia por ríos con un $\mathrm{pH}$ superior a la neutralidad (Fig. 7A), mientras que las otras dos reflejaron condiciones de acidez. Esta condición ácida y de muy escasa mineralización en el agua es compartida por las subcuencas y lagunas donde se hallaron tanto $S$. lacustris, como especialmente $H$. baileyi. Habiendo sido localizadas las poblaciones de esta especie en los ríos Tera, Negro y Agueda en sintopía estricta con la náyade Margaritifera margaritifera Linnaeus, 1758, un bivalvo típico de ríos oligotróficos con aguas turbulentas, oxigenadas y con bajo contenido en carbonato cálcico disuelto (Morales et al., 2004). No se han podido encontrar esponjas sobre la concha de estos moluscos, tal y como citan Manconi \& Pronzato (2002) para otros bivalvos. En el tramo medio del río Negro, donde habita la principal metapoblación de M. margaritifera del Duero en España, se han citado en simpatría con distribución parapátrica tres especies, siendo las dos más relacionadas con las condiciones de oligotrofia sus poblaciones más significativas. Mientras que en el Tera-medio, en el tramo ocupado por la náyade, se han citado también las tres especies, pero en este caso con distribución alopátrica por tramos. Siendo S. lacustris la especie que aparece a lo largo de todo el tramo de distribución común.

Las esponjas de agua dulce pueden habitar en un amplio espectro de condiciones ambientales y físicoquímicas del agua a lo largo del año, por lo que no han sido consideradas en los trabajos de caracterización de calidad de ecosistemas epicontinentales: tal y como lo han sido otros grupos, incluidos tradicionalmente en los "macroinvertebrados" bioindicadores (González \& Cobo, 2006). De hecho, no hay ninguna especie incluida en la normativa europea (Directiva de Hábitats, D43/92/CEE) ni española (Catálogo Español de Especies Amenazadas, RD139/2011), ni tampoco en los libros rojos. Por el momento el estatus de conservación de este grupo no ha sido abordado y su conservación queda bajo la protección genérica de especies con las que la conviven como los peces y los anfibios (Manconi \& Pronzato, 2008). Esta circunstancia ha propiciado un cierto olvido en cuanto a su estudio, y también una cierta tendencia a menospreciar cuantitativamente la importancia relativa en el funcionamiento de los ecosistemas acuáticos de estas especies filtradoras que pueden llegar a ocupar grandes superficies sumergidas (Dröscher \& Waringer, 2007). Si bien, su capacidad tapizante de superficies sumergidas está sometida a la competencia por los lugares de arraigo para las quimeras con el resto de la comunidad epilítica; pudiendo estar la parte del ejemplar más directamente expuesta a la luz solar asociado con microbios y carecer de éstos en la parte más oculta (Fig. 8F, sobre un tronco sumergido).

Nuestros datos iniciales sobre este grupo faunístico parecen indicar que se trata de seres que habitan en aguas transparentes, a veces distróficas, y que son sensibles a la turbidez del agua producida especialmente por los sólidos inertes en suspensión y por la materia orgánica particulada, aunque apenas estamos empezando a conocer su presencia en los ríos ibéricos. Aspecto éste mucho menos implementado en la monitorización de ríos y lagunas que otros como los nutrientes disueltos o la mineralización; y que podría resultar clave en el conocimiento de los mecanismos de funcionamiento de los ecosistemas acuáticos ibéricos y la consiguiente aplicación de medidas de gestión derivadas de la Directiva Marco del Agua (DMA, D2000/60/CE) para alcanzar el estado favorable de conservación en 2015.

\section{Agradecimientos}

Las preparaciones fueron realizadas por Marta Ortiz en el Servicio de Microscopía de la Universidad de Salamanca y las microfotografías SEM fueron realizadas en el Centro de Láseres Pulsados Ultracortos Ultraintensos (CLPU) del Parque Científico de la Universidad de Salamanca. Los ejemplares utilizados se encuentran depositados en el Área de Biología Animal. Los datos fisico-químicos pertenecen a las redes oficiales de calidad del agua (MAGRAMA, http://www.chduero.es/). M. Maldonado y A. Traveset nos aportaron valiosos comentarios que mejoraron el primer borrador de este trabajo. Marcos González y Fernando Cobo amablemente nos confirmaron citas próximas de esponjas en aguas de Galicia.

\section{Referencias}

Dröscher, I. \& Waringer, J., 2007. Abundance and microhabitats of freshwater sponges (Spongillidae) in a Danubean floodplain in Austria. Freshwater Biology, 52: 998-1008. http://dx.doi.org/10.1111/j.1365-2427. 2007.01747.x

Frost, T., Reiswig, H. M. \& Ricciardi, A., 2001. Porifera. In: E. Thorp \& A. P. Covich (eds.). Ecology and classification of North American freshwater invertebrates, $2^{\text {nd }}$ edition. Academic Press. San Diego: 97-133.

Gertner, C. H., Glöckner, F. O., Krohne, G. \& Hentschel, U., 2005. Microbial diversity of the freshwater sponge Spongilla lacustris. Microbial Ecology, 50: 206-212. http://dx.doi.org/10.1007/s00248-004-0172-x.

Gil Quilez, M. J., 1986. Organic microscopic remains in Miocene lacustrine sediments near Libros (Teruel, Spain). Hydrobiologia, 143: 209-212. http://dx.doi. org/10.1007/BF00026663.

González, M. \& Cobo, F., 2006. Macroinvertebrados de las aguas dulces de Galicia. Hércules de Ediciones. A Coruña. 174 pp. 
Gugel, J., 2001. Life cycles and ecological interactions of freshwater sponges (Porifera, Spongillidae) in the river Rhine in Germany. Limnologica, 31: 185-198. http://dx. doi.org/10.1016/S0075-9511(01)80020-7.

Margalef, R., 1955. Comunidades bióticas de las aguas dulces del noroeste de España. Publicaciones del Instituto de Biología Aplicada, 21: 5-85.

Manconi, R. \& Pronzato, R., 1991. Life cycle of Spongilla lacustris (Porifera, Spongillidae): a cue for environmentdependent phenotype. Hydrobiologia, 220: 155-160. http://dx.doi.org/10.1007/BF00006548.

Manconi, R. \& Pronzato, R., 2002. Suborder Spongillina subor. nov.: Freshwater Sponges. In: J. Hooper \& R. W. M. van Soest (eds.). Systema Porifera: A guide to the Classification of Sponges, Vol. 1. Kluwer Academic. New York: 921-1021.

Manconi, R. \& Pronzato, R., 2008. Global diversity of sponges (Porifera: Spongillina) in freshwater. Hydrobiologia, 595: 27-33. http://dx.doi.org/10.1007/s10750007-9000-x.

Morales, J. J., Negro, A. I., Lizana, M., Martínez, A. \& Palacios, J., 2004. Preliminary study of the endangered populations of pearl mussel Margaritifera margaritifera (L.) in the River Tera (Northwest Spain): habitat analysis and ases for their management. Aquatic Conservation: Marine and Freshwater Ecosystems, 14: 587-596. http:// dx.doi.org/10.1002/aqc.624.

Mildner, V. P., 1995. Sußwasserschwämme (Porifera, Spongillidae) aus Kärnten. Carinthia II, 185/105: 449-459.

Økland, K. \& Økland, J., 1996. Freshwater sponges (Porifera: Spongillidae) of Norway: distribution and ecology. Hydrobiologia, 330: 1-30. http://dx.doi.org/ 10.1007/BF00020819.

Oscoz, J., Tomás, C. \& Durán, C., 2009. New records of Eunapius fragilis (Leidy, 1851) and Ephydatia fuviatilis (Linnaeus, 1759) (Porifera, Spongillidae) in Ebro River Basin (N Spain). Limnetica, 28(2): 185-188.
Poirrier, M., 1974. Ecomorphic variation in gemmoscleres of Ephydatia fluviatilis Linnaeus (Porifera: Spongillidae) with comments upon its systematics and ecology. Hydrobiologia, 44(4): 337-347. http://dx.doi. org/10.1007/BF00036300.

Potts, E., 1887. Fresh Water Sponges. A monograph. Academy of Natural Sciences of Philadelphia. Philadelphia. iv + pp. 157-279. 12 láms. http://dx.doi.org/10.5962/ bhl.title. 12143 .

Pronzato, R. \& Manconi, R., 2001. Atlas of European freshwater sponges. Annali del Museo Civico di Storia Naturale di Ferrara, 4: 3-64.

Roovere, T., Loppa, A., Reintamma, T., Kuusksalu, A., Richelle-Maurerc, E. \& Kelvea, M., 2006. Freshwater sponges in Estonia: genetic and morphological identification. Proceedings of the Estonian Academy of Sciences, Biology and Ecology, 55(3): 216-227.

Schletterer, M. \& Eggers, T. O., 2006. Evidence of Freshwater Sponges (Porifera: Spongillidae) in the Upper Volga River (Russia). Berichte des Naturwissenschaftlich Medizinischen Vereins in Innsbruck, 93: 73-84.

Stephens, J., 1912. Freshwater Porifera. Proceedings of the Royal Irish Academy, 31(60): 1-18.

Traveset, A., 1986. Clave de identificación de las esponjas de agua dulce de la Península Ibérica. Asociación Española de Limnología, Claves de identificación de la flora y fauna de las aguas continentales de la Península ibérica, $\mathrm{n}^{\circ} 2.25 \mathrm{pp}$.

Traveset, A., 1991. Presencia d'Ephydatia fluviatilis (Porifera: Spongillidae) en un torrent de Mallorca. Bolletí de la Societat d'Història Natural de les Balears, 34: 97-98.

Uriz, M. J., 1986. Clave de identificación de las esponjas más frecuentes de la Península Ibérica. Miscel-lània Zoològica, 10: 7-22. 